\title{
STUDY ON SUSTAINABLE CARPET TILE FLOORING IN 5-STAR HOTEL OF INDIA
}

\author{
Ayushi Jain $^{1^{*},}$ Ar. Sweta Choudhary ${ }^{2}$ \\ ${ }^{l} P G$ Student, Sustainable design, Vivekananda Global University, Jaipur, Rajasthan (India) \\ ${ }^{2}$ Associate Professor, Vivekananda Global University, Jaipur, Rajasthan (India)
}

Article DOI: https://doi.org/10.36713/epra7447

DOI No: 10.36713/epra7447

\begin{abstract}
Sustainable development is a rapidly growing area of focus for many interior design professionals. The hospitality sector of the world's economy is growing. The environmental design of hotels can reduce the environmental impacts of growing tourism development. Interior designers can help influence this lasting movement through a suitable selection of interior finish materials that both meet the needs of our customers and could support this enduring commitment to change.

The focus of this paper is to study the carpet tile floors used in hotels. The purpose of this study is designers' important elements when highlighting the hotel with always design to consider evaluating floor materials for use.

Research articles related to the design of the hotel have also been analyzed. The results of the material analysis shows that the design of a hotel Good consumers feelings, self-brand links, satisfaction, preference, intentions of behavior and loyalty, beauty employees can affect enjoyment and well-being. Other contributions to hotel design Successful at business employment levels, maintenance costs, sales, increased efficiency, higher total operating profits, reduced capital and reduced investment need. The design of the hotel is also closely linked to stability.
\end{abstract}

\section{INTRODUCTION}

Sustainable development can be defined as development that meets the needs of the present without compromising on the ability of future generations to meet their own needs.

To have an effect on static stabilization. "Focus on planning from the point of view of the communication system of the Internet environment, solutions for the inter floor environment and for the environment, which are subjects for the interaction of the atmosphere and life". The weather may try to be updated at the same time in the weather. The tourism sector of the world economy is growing. The environmental design of hotels can reduce the environmental impacts of rapid tourism development. Interior designers can help influence this sustainable movement through the appropriate selection of interior finish materials that both meet the needs of our clients and support this enduring commitment to change. The focus of this paper is to study the carpet tile flooring used in hotels. The purpose of this study is to define the benefits of carpet tiles for designers and to shed light on the important elements to consider when evaluating flooring materials for use in hotels with sustainable designs.

Hotel design is closely related to sustainability as well. As a designer we need to finalize good durable flooring material for hotel space.

\section{CARPET TILE FLOORING}

1. CARPET TILE FLOORING?

Carpet tiles are small swatches of big carpet, made from broadloom carpet, that can be installed and combined in a number of creative ways. Also known as "modular carpets" \& "carpet squares", carpet tiles are most often square and available in a range of square sizes - 48 x 48, 50 x 50, 60 x 60 and 96 x $96 \mathrm{~cm}$. Some manufacturers, however, also offer carpet tiles in a variety of creative shapes. They are equipped with all comfortable facilities. 


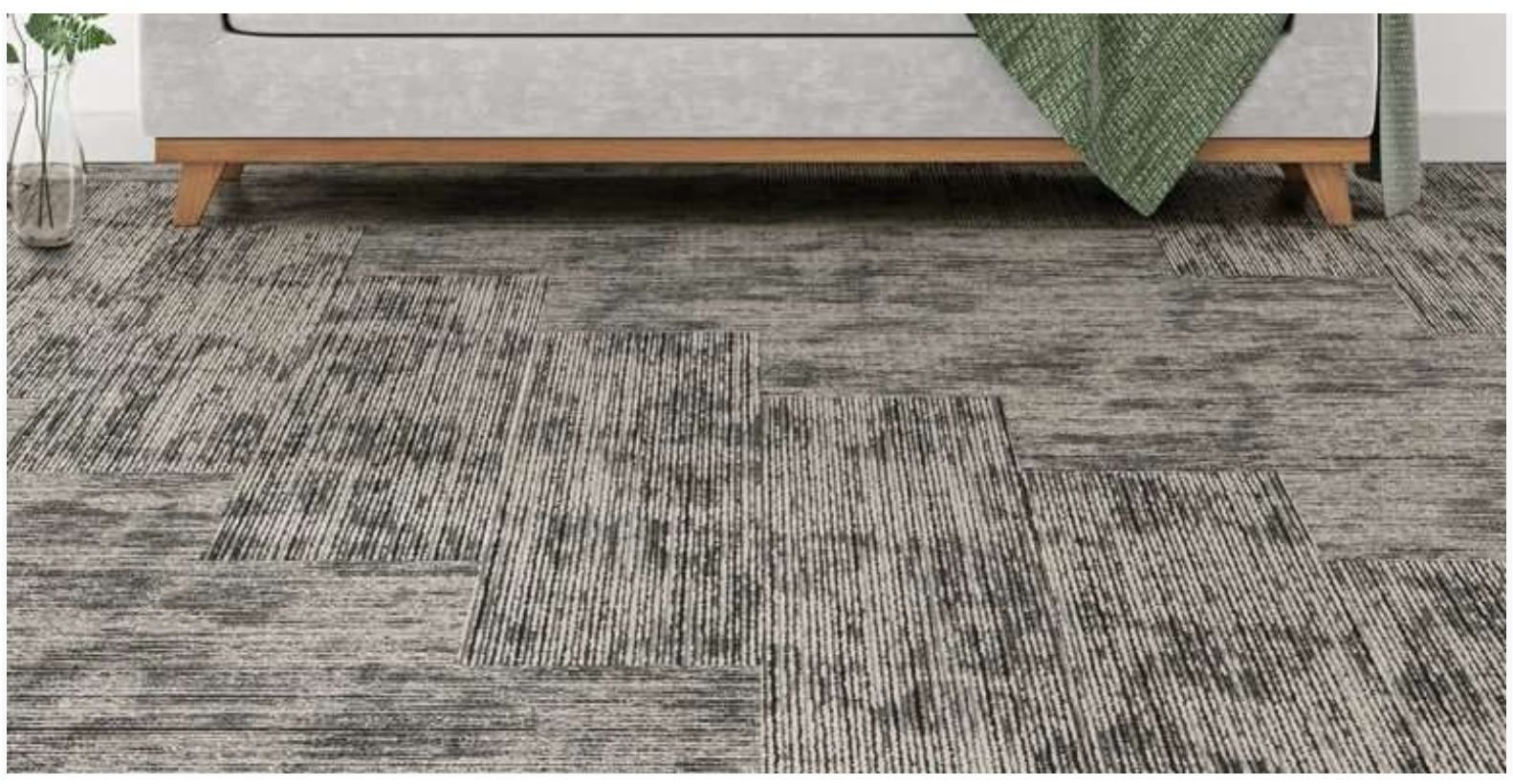

Figure 1 CARPET TILES

\section{BENEFITS OF CARPET TILE FLOORING}

\subsection{THEY ARE MODULAR}

These carpet tiles are 4 times more efficient as compared to broadloom carpet. Modular tiles are not only easy to fit, they are much easier to store.

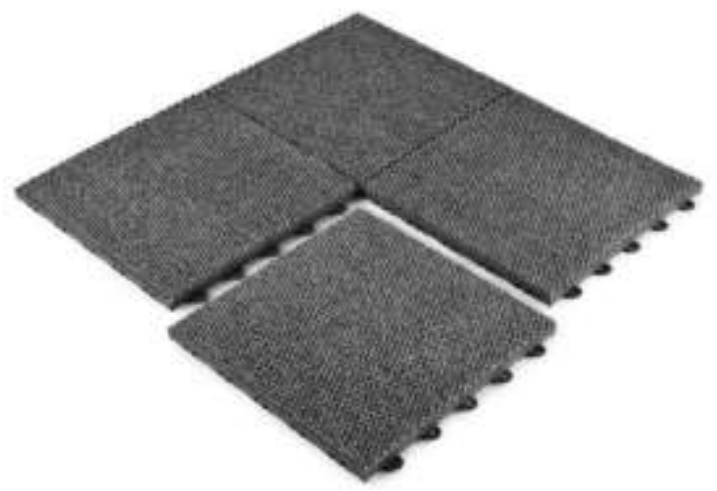

Figure 2 INTERLOCKING CARPET TILES

\section{EASE OF INSTALLATION}

One of the main reason architects and designers - not to mention floor fitters - choose to work with carpet tiles is the ease with which they can be installed. Let's find out how Carpet can make your installation easier:

- Carpet tiles are easy to pick up and transport, which makes it easy to get them to the work site without getting damaged in the first place.

- Carpet tiles, because they are pre-backed, can be installed directly over the subfloor, eliminating the need for an underlay. It saves a lot of time and effort not to mention money.

- Carpet tiles do not always need to be adjusted, or set in place, for 24 hours before laying.

- While absolutely not recommended, carpet tiles can also be placed alongside furniture in situations where time is of the essence. 


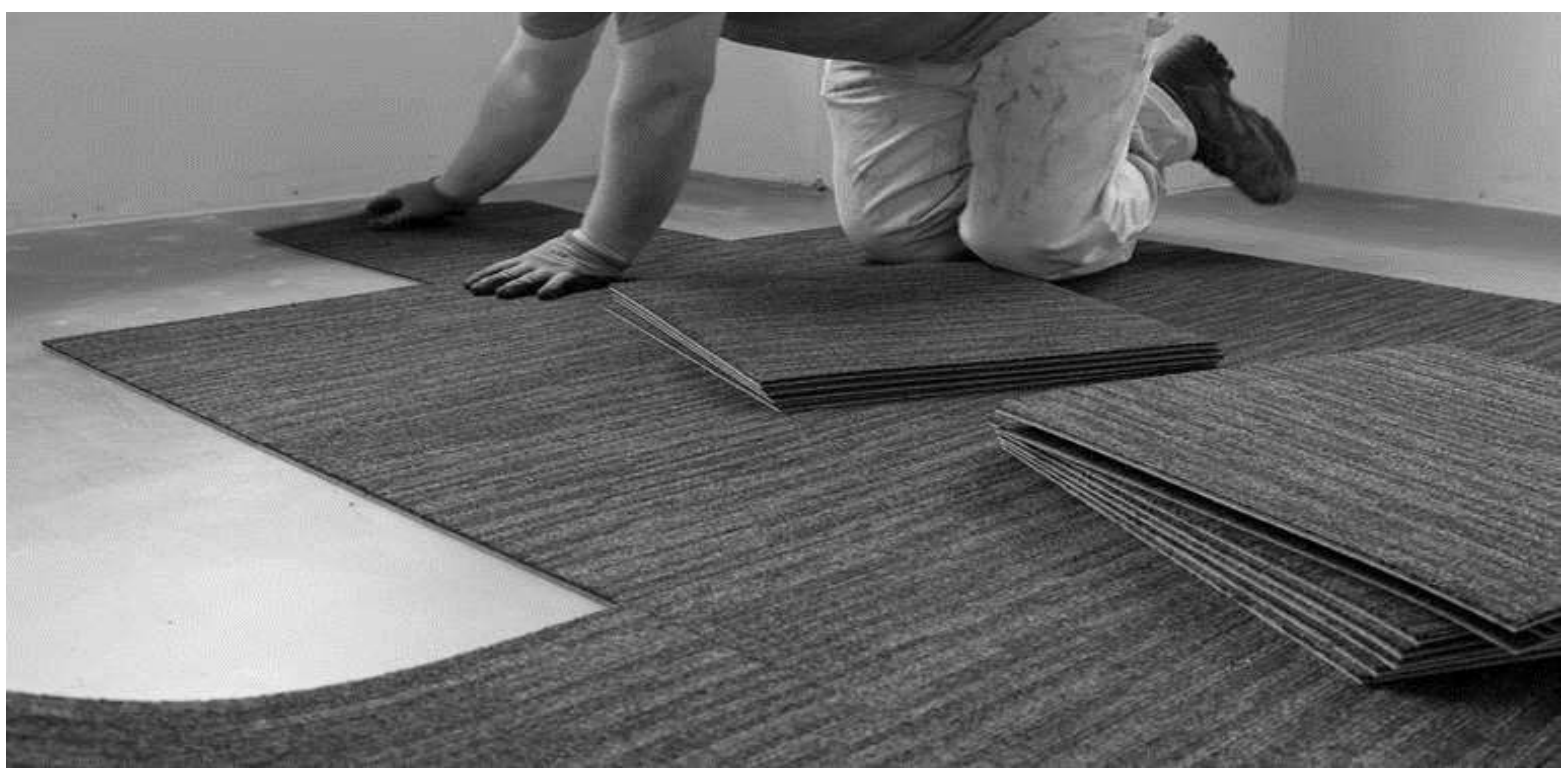

Figure 3 CARPET TILE INSTALLATIO

\subsection{THEY ARE SUSTAINABLE}

Sustainability is an increasingly important consideration for architects and designers, as well as the clients they design. Because of the minimal waste that carpets tiles create in installation, choosing them for your design means you are already on your way to sustainability. On top of that, they are recyclable, olefinbased raw materials for backing to help create "free-to-" carpeting (eg, Phthalate-free, Polyvinyl Chloride (PVC)-free, Bitumen-free, Styrene-free).

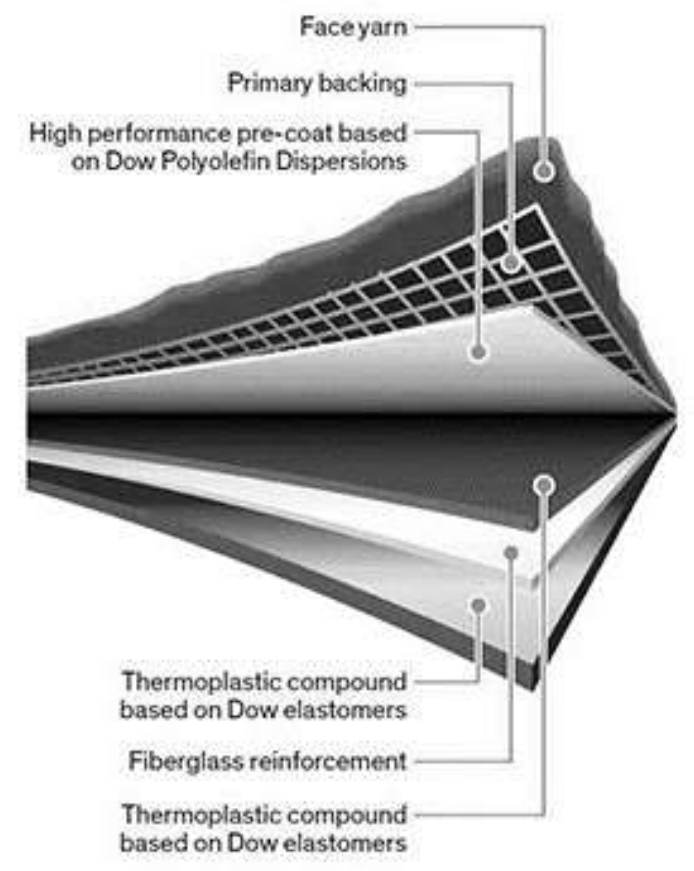

Figure 4 DECONSTRUCTED CARPET TILE 


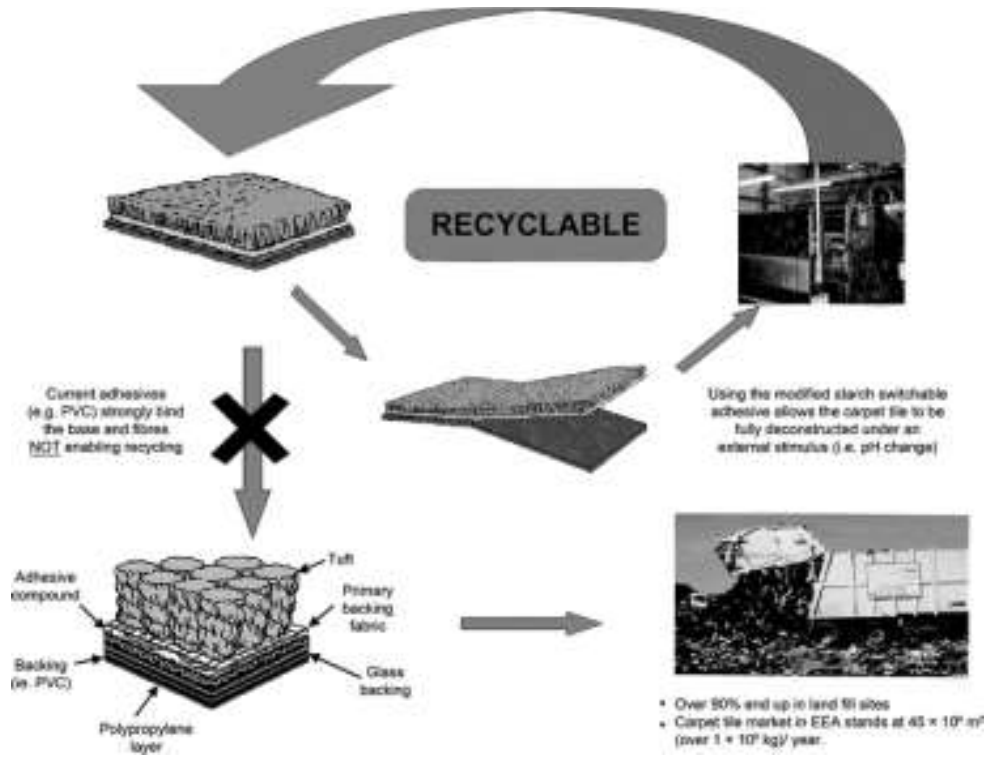

Figure 5 RECYCLABLE CARPET TILE

\subsection{THEY ARE DURABLE}

We do our Color Fastness Test (a test designed to use color changes due to light and wear on the surface of the carpet), the Castor Chair Test (to simulate the effect of Castor chairs used in commercial spaces on carpets) designed test) go beyond standard wear and tear testing. Vetterman Drum Test (test designed to simulate continuous moving traffic).

\subsection{THEY ARE VERSATILE}

Individual tiles can be easily replaced if damaged, or if you just want a change. They're also easy to mix and match - so you can get creative and work tile-by-tile.
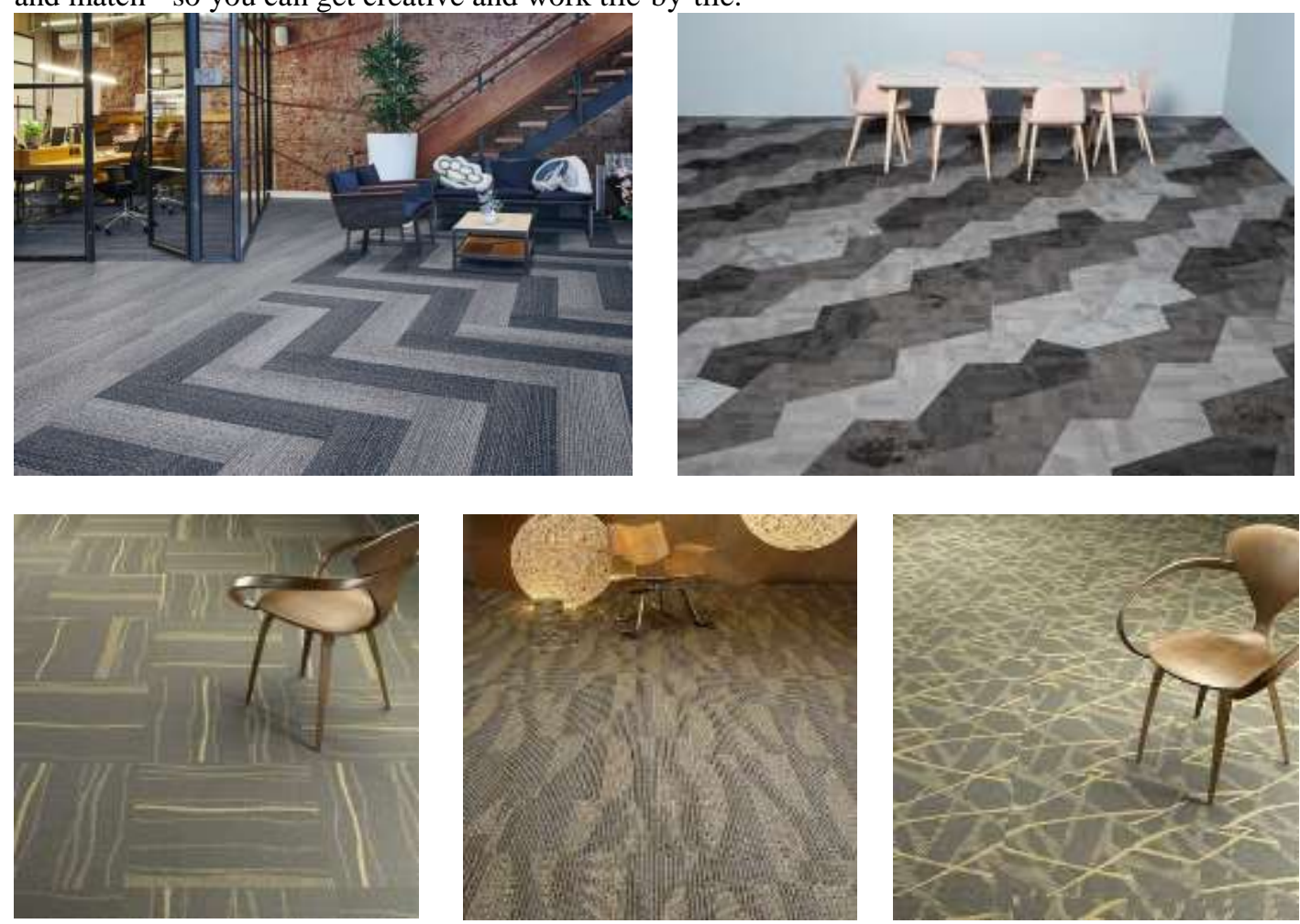


\subsection{THEY PROVIDE INDOOR AIR QUALITY}

Indoor air quality has been proven to affect the health, well-being and productivity of the people living in a space. Breathe easily with carpet that protects against the growth of mold, mildew and other odor-causing microorganisms.

\subsection{THEY OFFER GOOD ACOUSTICS}

Soundproofing flooring is the ideal solution for reducing the impact of noise in any space, and at Interface, we design our products with acoustics in mind.

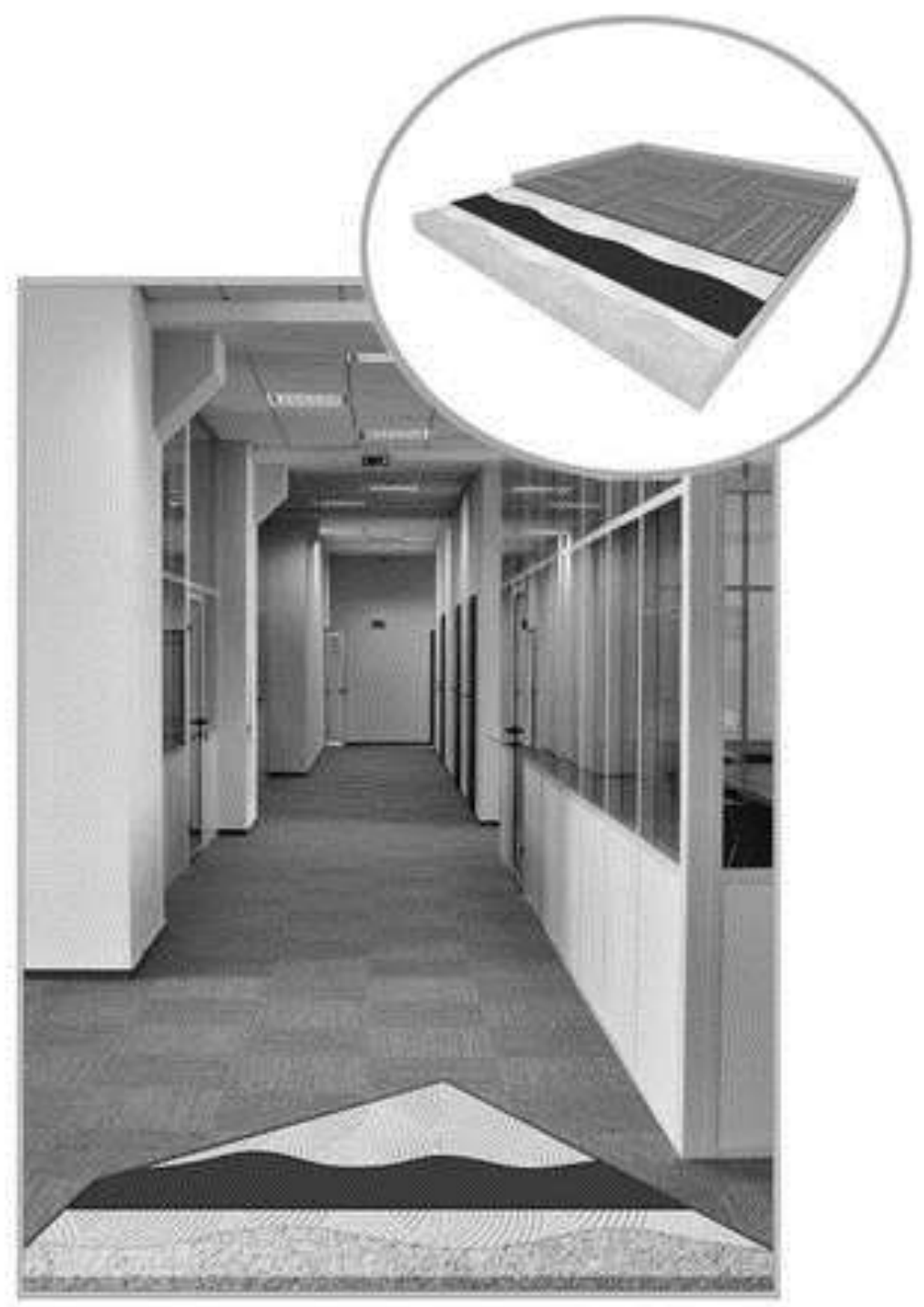

Figure 6 DESIGN OF CARPET TILES AS PER ACOUSTICS

\subsection{THEY ARE CHEAP}

Together, all these benefits make carpet tiles excellent value for money.

\subsection{LOW MAINTENANCE}

With carpet tiles, maintenance is simple. Tiles can be cleaned with normal spot cleaning, and can be easily replaced if excessively soiled or destroyed. To stay on top of maintenance efforts, however, you and your customer will need to figure out which areas of the carpet will be most affected by heavy dirt and create a plan to address these areas. 


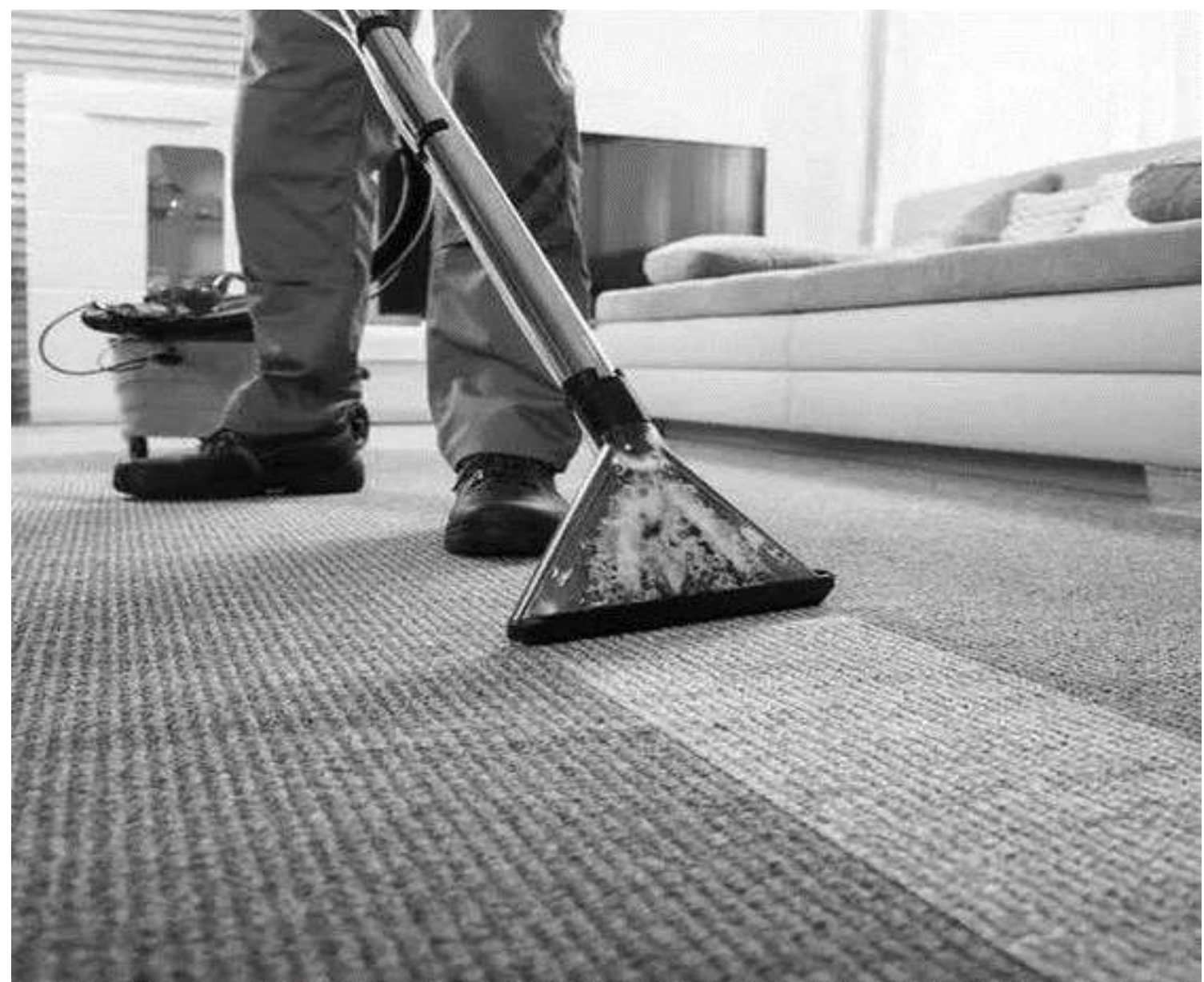

Figure 7 CARPET TILE CLEANING

\subsection{GENERATE LESS WASTE}

Carpet tiles generate minimal waste at the fitting stage. This is because very little cutting, or adjustment, is required to fit the tiles in a certain location. This is especially true for rooms with many nooks and odd angles.

You can expect a wastage of around 1-3\%. Less waste means less money to spend, but is also attractive to customers concerned about sustainability.

3. CARPETS AND RUGS ARE USED AT FOLLOWING PLACES:

1.banquet halls 2. Hotel lobby 3. Corridors 4. Presidential suites 5.Vice-presidential suites 6. Villas 7.

Resort's restaurants 

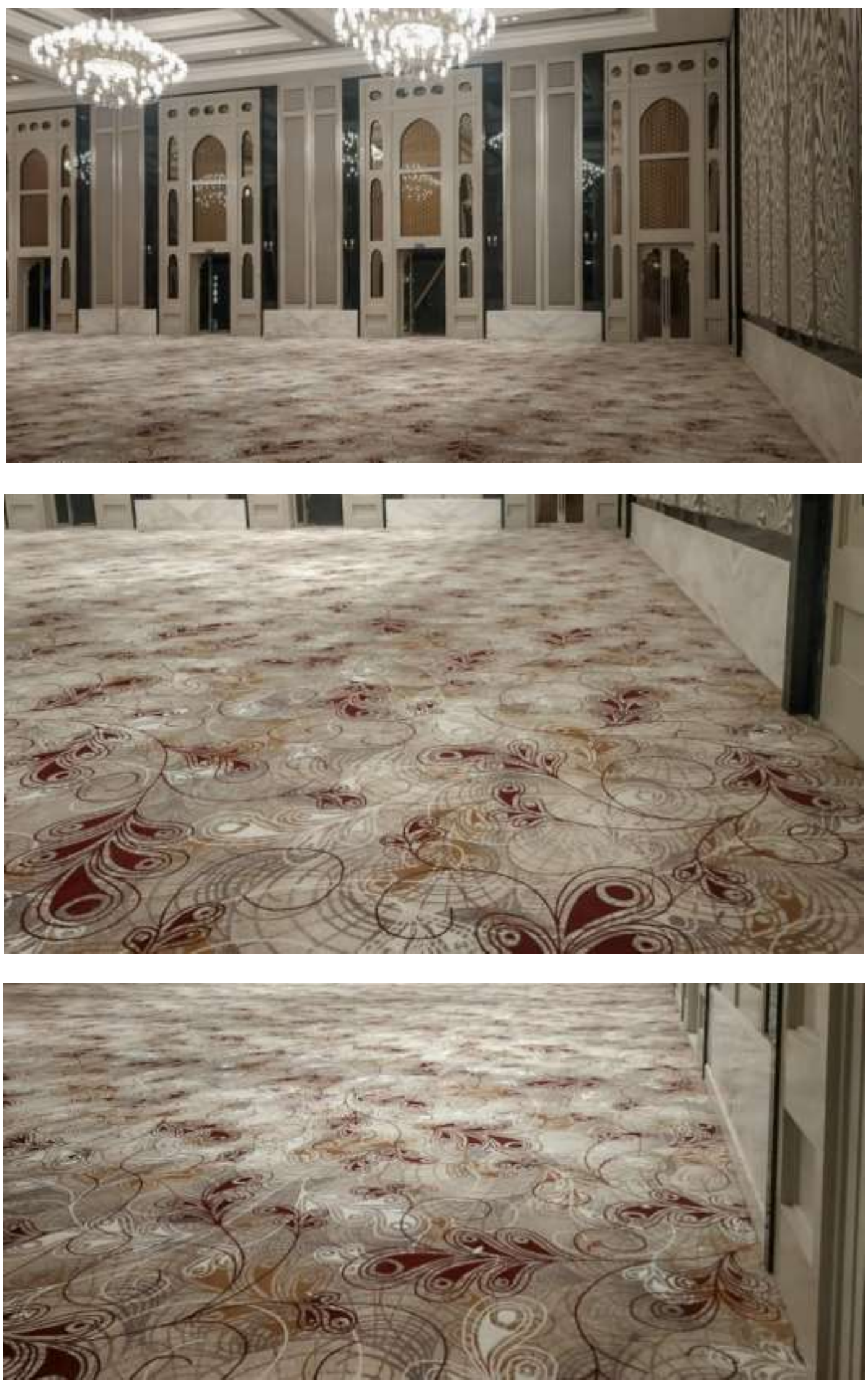

Figure 8 JW MARRIOTT HOTEL BANQUET HALL, JAIPUR 


\section{CARPET CAN AFFECT YOUR LEED APPLICATION HOW}

Sustainable Carpets can add credit to your application with the US Green Building Council (USGBC), the organization that developed the LEED certification and which works to promote sustainable construction policies nationwide.

Carpeting can play a major role in the overall sustainability of your project. Think about the amount of surface area of your building that is covered by floors - this is a big part of your project, so, of course, the carpet you choose will have a significant impact on the eco-friendliness of your building.

Although the USGBC does not certify building materials, sustainable carpet can add credit to your LEED application if it is made from recycled materials, locally sourced, and/or made from low-emission materials.

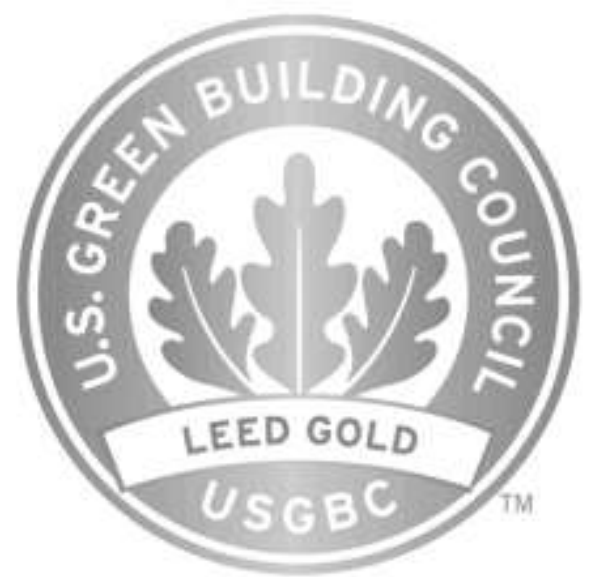

Figure 9 USGBC LEED LOGO

5. PRICE ON INDIAMART

Thickness - 6 - $8 \mathrm{~mm}$

Color - Multi

Size $\quad-600 \mathrm{~mm}$ X 600mm

Price $\quad-₹$ 50/ Square Feet- ₹ 100/ Square Feet (Jaipur, Rajasthan)

\section{CONCLUSION}

There are many sustainable carpet options stemming from recycled materials.

When people think of green flooring options, sustainable hardwood, bamboo and cork are often some of the first materials that come to mind. However, carpet can be a great eco-friendly solution, and choosing the right carpet can also increase the LEED application of your building.

They are made in lots of colours and patterns so you can create your own unique designs. Plus, the installation is simple and a great DIY project. You can also install wall-to-wall carpet tiles, which is a bit more challenging.

Carpet tiles, sometimes called carpet squares, come in modular sizes such as 18 " x 18" and 24" x 24" that are ideal for creating geometric patterns, and many manufacturers make half- and quarter-size tiles. Huh. so that you make your own design.

\section{REFERENCES}

1. https://www.interface.com/IN/en-IN/Products-IN/Carpet-tile/Carpet-Tiles-Benefits-en_IN

2. https://www.heritagecarpets.sg/project/india-jaipur-jw-marriott-hotel-banquet-hall-project/

3. https://blog.egecarpets.com/explore/everything-you-need-to-know-about-carpet-tiles 